\title{
Proteomic analysis of human scleroderma fibroblasts response to transforming growth factor-8
}

Benjamin Chaigne ${ }^{1-4}$, Guilhem Clary ${ }^{1,2,5}$, Morgane Le Gall ${ }^{1,2,5}$, Nicolas Dumoitier ${ }^{1-3}$, Claire

Fernandez $^{1-4}$, Sebastien Lofek ${ }^{1,2}$, Philippe Chafey ${ }^{1,2,5}$, Pia Moinzadeh ${ }^{6}$, Thomas Krieg ${ }^{6}$, Christopher P.

Denton $^{7}$, and Luc Mouthon ${ }^{1-4}$

${ }^{1}$ INSERM U1016, Institut Cochin, Paris, France ;

${ }^{2}$ CNRS UMR 8104, Paris, France ;

Université Paris Descartes, Sorbonne Paris Cité, Paris France ;

${ }^{4}$ Service de Médecine Interne, Centre de Référence Maladies Systémiques Autoimmunes Rares, vascularites nécrosantes et sclérodermie systémique, Hôpital Cochin, Assistance Publique-Hôpitaux de Paris, Paris, France ;

${ }^{5}$ Proteomic core facility of Paris Descartes University (3P5), Paris, France

Department of Dermatology, University of Cologne, Germany

${ }^{7}$ Institute of Immunity and Transplantation, Centre for Rheumatology and Connective Tissue

Diseases, Royal Free Hospital, London, United Kingdom

\section{Correspondence to:}

Pr Luc Mouthon, INSERM U1016, CNRS UMR 8104, 8 rue Méchain, 75014 Paris, France. Tel: +33

(0) 140516657 / Fax: +33 (0) 1405165 70. E-mail: luc.mouthon@aphp.fr

Received: 04 01, 2018; Revised: 07 14, 2018; Accepted: 08 20, 2018

This article has been accepted for publication and undergone full peer review but has not been through the copyediting, typesetting, pagination and proofreading process, which may lead to differences between this version and the Version of Record. Please cite this article as doi: $\underline{10.1002 / \text { prca.201800069. }}$.

This article is protected by copyright. All rights reserved. 
Total word count: 3612

\section{Abstract word count: 200}

\section{Abstract}

\section{Abstract (199 Words)}

Purpose. Systemic sclerosis (SSc) is characterized by autoimmunity, vasculopathy and fibrosis. Fibrosis is due to an activation of fibroblasts by the transforming growth factor- $\beta$ (TGF- $-\beta$ ). This study investigates the proteomic response of SSc fibroblasts to TGF- $\beta$.

Experimental design. Skin fibroblasts from diffuse SSc patients and healthy controls (HC) were cultured with or without TGF-ß. Two-dimensional differential in-gel electrophoresis and mass spectrometry (MS) combined with Ingenuity Pathway analysis (IPA) and Panther / David softwares analysed proteins differentially expressed between groups. Real-time cell analyser (RTCA) assessed fibroblast proliferation and viability.

Results. Two hundred and seventy nine proteins were differentially expressed between groups. Principal component analysis showed significant differences between groups. IPA showed specific process networks such as actin cytoskeleton and integrin signalling. Panther and David softwares showed predominant biological processes such as cellular and metabolic processes. TGF- $\beta$ enhanced protein synthesis and protein pathways. IPA and RTCA suggested the involvement of epidermal growth factor receptor (EGFR) and phosphatidylinositol 3 kinase (Pi3K).

Conclusions and clinical relevance. We confirmed that the proteome of fibroblasts differs between SSc patients and $\mathrm{HC}$ and demonstrated that fibroblasts exacerbate their proteomic phenotype upon stimulation with TGF- $\beta$. We highlighted EGFR and Pi3K as proteins of interest in SSc fibroblasts.

This article is protected by copyright. All rights reserved. 
KEYWORDS: proteomic; systemic sclerosis; fibroblasts; transforming growth factor $\beta$; epidermal growth factor receptor; phosphatidylinositol 3 kinase receptor.

\section{Clinical Relevance}

Systemic sclerosis is a severe disease characterized by autoimmunity, vasculopathy and fibrosis. Understanding mechanisms by which fibrosis is driven is an unmet need and could lead to finding new target and new treatment option in SSc.

In this study, we confirmed that the proteome of fibroblasts differs between SSc patients and HC and demonstrated that fibroblasts exacerbate their proteomic phenotype upon stimulation with TGF- $\beta$. These findings support the inhibition of fibroblasts and / or TGF- $\beta$ in SSc as a possible treatment of fibrosis.

Moreover, we highlighted EGFR and Pi3K as possible proteins of interest in SSc fibroblasts. Although these results needs to be confirmed by in vivo studies, there are monoclonal antibodies and chemical compounds, which are available are in development and target these pathways.

Conclusively, our works brings new evidence and suggest new targets to inhibit fibroblasts in patients with SSc.

\section{INTRODUCTION}

Systemic sclerosis ( $\mathrm{SSc}$ ) is an autoimmune connective tissue disorder characterized by immune activation, vascular hyper-reactivity, and fibrosis ${ }^{[1]}$. Fibrosis is a pathological process characterized by accumulation of connective tissue components leading to the destruction of the architecture of a tissue and/or an organ and/or the alteration of its function ${ }^{[2]}$. In SSc, it mainly affect the skin and the

This article is protected by copyright. All rights reserved. 
lungs but can be responsible for severe systemic features including gastro-intestinal tract and cardiac involvements causing much of the morbidity and mortality associated with the disease ${ }^{[3]}$.

Fibrosis is mostly due to an over production of collagen and proliferation of fibroblasts ${ }^{[4]}$. Activation of fibroblasts leads to their differentiation into myofibroblasts ${ }^{[5]}$. This activated phenotype goes along with a resistance to Fas-mediated apoptosis ${ }^{[6]}$, an increase in collagen synthesis and a defect of extracellular matrix component regulators ${ }^{[7]}$. Many factors have been proposed to be responsible for fibroblasts activation in SSc, including interleukin (IL)-4 ${ }^{[8]}$, IL-6 ${ }^{[9,10]}$, connective tissue growth factor ${ }^{[11]}$, platelet derived growth factor (PDGF) ${ }^{[12]}$, reactive oxygen species ${ }^{[13]}$, anti-fibroblast and antiPDGF receptor autoantibodies ${ }^{[14,15]}$ and last but not least transforming growth factor- $\beta$ (TGF- $\left.\beta\right)^{[16]}$.

TGF- $\beta$ is a pleotropic cytokine, belonging to the superfamily of signalling proteins, which regulate inflammation, vascular remodelling and fibrosis ${ }^{[16]}$. It is a cornerstone of SSc pathogenesis. Its gene signature is a hallmark of SSc profiling ${ }^{[17-19]}$. All three isoforms of TGF- $\beta$ are increased in the skin ${ }^{[20]}$, and skin and lung expression of TGF- $\beta$ regulated genes, thrombospondin-1 and cartilage oligomeric protein, correlates with disease activity ${ }^{[21]}$. Although myofibroblasts have their own secretion of TGF- $\beta$, other cells including monocytes and macrophages secrete or activate its preform. Our group has recently reported that $B$ cells also secrete TGF- $\beta$ to activate fibroblasts ${ }^{[10]}$. TGF- $\beta$ binds to TGF- $\beta$ receptors I and II at the surface of fibroblasts. Fibroblasts activation then requires the dimerization of the receptors and subsequent activation of the Smad proteins which in turn colocalized into the nucleus and activate transcriptional programs ${ }^{[22]}$. This activation is then responsible for fibroblasts proliferation, migration, differentiation and production of extracellular matrix components.

In addition to the acquisition of an activated phenotype and a defect in apoptosis, we wished to characterize the proteomic response of activated fibroblasts and hypothesized that fibroblasts response

This article is protected by copyright. All rights reserved. 
to TGF- $\beta$ might be biased. Therefore, we decided to investigate the proteomic response of skin fibroblasts to TGF- $\beta$ in patients with SSc.

\section{METHODS}

\section{Cells}

Skin biopsies were performed in involved skin of the forearm of 4 patients with diffuse SSc fulfilling the American College of Rheumatology (ACR) / European League Against Rheumatism (EULAR) criteria for the diagnosis of SSc (Supplemental Table 1) ${ }^{[23]}$. Normal human skin fibroblasts were cultured from skin biopsies obtained from 3 healthy controls (HC). All patients and controls gave their written informed consent according to the ethics committee of Cochin university hospital and in conformity with the principles outlined in the Declaration of Helsinki. They were included in the HTAP-Ig study (Investigation and clinical research's contract 2005, CIRC $\mathrm{N}^{\circ}$ 05066, and Programme Hospitalier de Recherche Clinique Nº P071209, promoter Assistance Publique - Hôpitaux de Paris). Biopsy specimen were cut into small pieces and seeded into Petri dishes and then into $175 \mathrm{~cm}^{2}$ plastic flasks. Patients and HC fibroblasts were grown in Dulbecco's modified Eagle's medium (DMEM) supplemented with $10 \%$ heat-inactivated fetal calf serum (FCS) obtained from Gibco (Life Technology, Saint-Aubin, France) at $37^{\circ} \mathrm{C}$ in $5 \% \mathrm{CO}$. All fibroblasts were kept separated during the experiments.

\section{Fibroblasts culture and sample preparation}

At the fourth passage, fibroblasts from each subject were starved (cultured 12 hours in DMEM without FCS) and then separately cultured in DMEM supplemented with 10\% heat-inactivated FCS in the presence or in the absence of $10 \mathrm{ng} / \mathrm{mL}$ of TGF- $\beta 1$ (Tebu-bio SAS, Le Perray en Yvelines, France) for 48 hours. Then, the four groups of fibroblast were harvested for protein extraction and centrifuged at $400 \mathrm{~g}$ for 7 minutes at $21^{\circ} \mathrm{C}$. Cells pellet (stored at $-80^{\circ} \mathrm{C}$ ) were then lysed in lysis buffer

This article is protected by copyright. All rights reserved. 
(8M urea, 2M thiourea, 4\% CHAPS, $60 \mathrm{mM}$ dithiothreitrol). Then the protein extracts were clarified by ultra-centrifugation at $100.000 \mathrm{~g}$ for 1 hour at $4^{\circ} \mathrm{C}$ as previously described ${ }^{[24,25]}$.

2-Dimensional differential in-gel electrophoresis, image analyses, in-gel trypsin digestion, and protein identification by mass spectrometry

The samples of the four different groups of fibroblast protein lysates were analyzed by 2-dimensional differential in-gel electrophoresis (2D DIGE). Sample preparation, labelling with CyDye DIGE fluor, 2D-gels electrophoresis, DeCyder analysis and protein identification by mass spectrometry are described according to A. Regent et al ${ }^{[24]}$ and H. Dib et al ${ }^{[26]}$.

Proteins of interest identified in each comparison had a fold change expression ratio greater than 1.3 or lower than -1.3 and a Student's t test $\mathrm{p}$-value $<0.05$.

\section{Functional classification}

To check for biological processes and pathways (expressed in GO terms) associated to significantly differentially expressed proteins, we uploaded our proteomic dataset into the Panther (protein annotation through evolutionary relationship) software (www.pantherdb.org) and the DAVID Bioinformatics Resources 6.8 software (https://david.ncifcrf.gov). Both softwares are based on a comprehensive classification system that combines gene function, ontology, and pathways, which enables the analysis of large-scale proteomic experiments ${ }^{[27]}$.

\section{Generation of biological network}

To generate biological pathways and networks, we uploaded the list of significantly differentially expressed proteins of our proteomic data sets into the Ingenuity Pathway Analysis (IPA®, QIAGEN Redwood City, www.qiagen.com/ingenuity). A pathway network with significant $p$-values $(p<0.05)$ was generated as previously detailed ${ }^{[24,25]}$.

This article is protected by copyright. All rights reserved. 


\section{xCelligence real-time cell analyzer}

To validate proteins of interest we measured the proliferation and the viability of fibroblasts when cultured in the presence or in the absence of different inhibitors. At the third passage of culture, fibroblasts from $\mathrm{HC}$ or SSc patients were plated in a 96-well plate at a concentration of 2500 cells/well in duplicate in the presence or in the absence of different inhibitors including trastuzumab (Herceptin $^{\circledR}$, Roche, Welwyn Garden City, United Kingdom), cétuximab (Erbitux ${ }^{\circledR}$, Merck, Lyon, France), LY-294,002 hydrochloride solid (Sigma-Aldrich, Saint-Quentin Fallavier, France), IC-87114 (Euromedex ${ }^{\circledR}$, Souffelweyersheim, France), or pictilisib (Euromedex ${ }^{\circledR}$, Souffelweyersheim, France). Proliferation and viability of fibroblasts were measured using xCelligence real-time cell analyzer (ACEA Biosciences Inc., San Diego, CA, USA) after three days of culture.

\section{Statistical analysis}

In 2D-DIGE experiments, protein content was compared with ANOVA test (gate keeper strategy). If significant, the Tukey's multiple comparison test was used to investigate between which groups the difference in protein expression is significant. Comparisons were made using DeCyder software. A $p$ value $<0.05$ was considered as statistically significant.

Results of survival and proliferation experiments in xCelligence real-time cell analyzer were compared with t-test or Mann-Whitney-test. All analyses were carried out using Prism 6 (GraphPad, La Jolla, CA, USA) with statistical significance defined as: $* p<0.05 ; * * p<0.01 ; * * * p<0.001$; $* * * * p<0.0001$

\section{RESULTS}

Comparison of proteins differentially expressed between fibroblasts from SSc patients and HC cultured in the presence or in the absence of TGF-ß

This article is protected by copyright. All rights reserved. 
Using DeCyder Image Analysis software, a mean \pm standard deviation of $2713 \pm 90$ spots could be matched to the reference gel and were used for the comparative analysis.

A total of 279 proteins were found as differentially expressed in at least one of those group comparisons: SSc fibroblasts cultured in the absence of TGF- $\beta$ (SSc) $v s$ fibroblasts from healthy controls cultured in the absence of TGF- $\beta$ (HC); SSc $v s$ fibroblasts from healthy controls cultured in the presence of TGF- $\beta$ (HCT); SSc fibroblasts cultured in the presence of TGF- $\beta$ (SScT) vs SSc; SScT vs HCT; HCT vs HC. Principal component analysis (PCA) was performed on the proteins of interest and showed four different clusters of proteome (Figure 1A and Supplemental Figures 1-2). Component 1 contributed to $60.9 \%$ of the cumulative variance while Component 2 contributed to $11.2 \%$ of the cumulative variance. A hierarchical clustering of protein displayed as a heat map was also generated, confirming four discriminant clusters between fibroblasts from SSc patients and $\mathrm{HC}$ cultured in the presence or in the absence of TGF- $\beta$ (Figure 1B).

Those 279 spots of interest were identified by mass spectrometry.

\section{Comparison of proteins differentially expressed between SSc and $\mathrm{HC}$ fibroblasts cultured in the} absence of TGF-ß

Forty-two proteins were significantly differentially expressed between SSc and $\mathrm{HC}$ fibroblasts cultured in the absence of TGF- $\beta$ (Table 1 and Supplemental Table 2). These proteins were involved in actin cytoskeleton signalling and integrin signalling as well as remodelling of epithelial adherens junctions. Several proteins were upregulated in SSc fibroblasts with a high difference in fold change of expression when compared to HC: Trio and F-actin binding protein which plays a role in actin modification, cell adhesion and cytoskeletal organisation (fold change 2.9), myosin 9 which plays a role in muscle contraction (fold change 2.15), and LIM domain and actin-binding protein 1 which regulates actin polymerization (fold change 1.9). Several proteins were also downregulated in SSc

This article is protected by copyright. All rights reserved. 
fibroblasts with a high difference in fold change of expression when compared to HC: ras GTPaseactivating-like protein IQGAP1 which plays a role in the signalling pathway of fibroblast growth factors (fold change -1.7), ubiquitin-like modifier-activating enzyme (fold change -1.6), and major vault protein which plays a role in cell proliferation and in the negative regulation of protein tyrosine kinase activity and in the negative regulation of cell signalling (fold change -1.6). Using Panther and David classification systems, the most predominant gene ontology biological processes were cellular process, metabolic process and cellular component organization or biogenesis (Table 2 and Supplemental Figure 3). These proteins are involved in several pathways including mainly integrin signalling pathways, adhesion, cytoskeleton regulation, and also PI3K pathway (Table 3 and Supplemental Figure 4).

\section{Comparison of proteins differentially expressed between SSc (SScT) and HC (HCT) fibroblasts cultured in the presence of TGF-B}

Thirty-four proteins were significantly differentially expressed between SScT and HCT (Table 1 and Supplemental Table 3). These proteins were involved in citrulline biosynthesis or metabolism as well as the signalling pathway implicating Rho Family GTPases. Several proteins were upregulated in SScT with a high difference in fold change of expression when compared to HCT: tropomyosin $\beta$ chain which plays a role in muscle contraction (fold change 3.3) (Supplemental Figure 5), myosin regulatory light polypeptide 9 which plays a role in muscle contraction (fold change 3.0), and caldesmon which plays a role in muscle contraction, actin assembly and response to TGF- $\beta$ stimulus (fold change 2.3). Several proteins were also downregulated in SScT with a high difference in fold change of expression when compared to HCT: prolyl endopeptidase FAP which plays a role in proteolysis (fold change -1.9), vimentin (fold change -1.6), and U6 snRNA-associated Sm-like protein (fold change -1.6). Using Panther and David classification systems, the most predominant gene ontology biological processes were also cellular process, metabolic process and cellular component

This article is protected by copyright. All rights reserved. 
organization, including cellular adhesion, epithelial differentiation, muscle contraction (Table 2 and Supplemental Figure 3). These proteins are involved in several pathways including mainly FAS signalling pathways, cytoskeleton regulation, and microRNAs (Table 3 and Supplemental Figure 4).

\section{Comparison of proteins differentially expressed in fibroblasts from SSc patients cultured in the presence (SScT) or in the absence (SSc) of TGF- 8}

Two hundred and thirty five proteins were significantly differentially expressed between SScT and SSc (Table 1 and Supplemental Table 4). These proteins were also involved in actin cytoskeleton signalling and integrin signalling (Supplemental Figure 3). Several proteins were upregulated in SScT with a high difference in fold change of expression when compared to SSc: tropomyosin $\alpha 1$ chain (fold change 6.7), procollagen-lysine,2-oxoglutarate 5-dioxygenase 2 (fold change 4.6), and calponin 3 which plays a role in actomyosin structure organization (fold change 4.1). Several proteins were also downregulated in SScT with a high difference in fold change of expression when compared to SSc: protein S100-A4 (fold change -2.9), vimentin which plays a role in cellular response to fibroblast growth factor stimulus, cytoskeleton organization (fold change -2.8), and elongation factor 2 (fold change -2.8). Using Panther and David classification systems, the most predominant gene ontology biological processes were also cellular process, metabolic process and cellular component organization, including cellular adhesion, and oxidation-reduction process (Table 2 and Supplemental Figure 3). These proteins recruited more pathways than previous comparison. Such pathways are mainly involved in several pathways including mainly integrin signalling pathways, metabolic pathways, and cytoskeleton regulation (Table 3 and Supplemental Figure 4).

\section{Comparison of proteins differentially expressed in $\mathrm{HC}$ fibroblasts cultured in the presence (HCT) or in the absence (HC) of TGF-ß}

This article is protected by copyright. All rights reserved. 
One hundred and sixty two proteins were significantly differentially expressed between HCT and HC (Table 1 and Supplemental Table 5). These proteins were also involved in actin cytoskeleton and integrin signalling. Several proteins were upregulated in HCT with a high difference of expression when compared to $\mathrm{HC}$ : tropomyosin $\beta$ chain (fold change 8.5 ), tropomyosin $\alpha 1$ chain (fold change 8.4), and procollagen-lysine, 2-oxoglutarate 5-dioxygenase 2 (fold change 6.6). Several proteins were also downregulated in HCT with a high difference of expression when compared to HC: vimentin (fold change -3.4), dihydropyrimidinase-related protein 2, which plays a role in cell differentiation and cytoskeleton organization (fold change -2.6), and leucine-rich PPR motif-containing protein (fold change -2.5). Using Panther and David classification systems, the most predominant gene ontology biological processes were also cellular process, metabolic process and cellular component organization, including cellular adhesion (Figure 2 and Supplemental Figure 3). As for fibroblasts from patients with SSc, proteins differentially expressed in the presence of TGF- $\beta$ are able to recruit more pathways than proteins differentially expressed between fibroblasts from SSc patients and fibroblasts from HC. Such pathways are also mainly involved in several pathways including integrin signalling pathway, adhesion pathways, and cytoskeleton regulation (Table 3 and Supplemental Figure 4).

\section{Biological network analysis of identified proteins}

Using data on the proteins that were differentially expressed between $\mathrm{HC}$ and SSc, we used IPA to generate a user-built network focusing on direct interactions and human proteins showed in Figure 2. Of note, TGF- $ß 1$ was found to be in interaction with identified proteins. Interestingly, the epidermal growth factor receptor (EGFR) and the p85 subunit of the phosphatidylinositol 3 - kinase (Pi3K) receptor were also found as central proteins of the network.

\section{Proliferation and survival of fibroblasts with EGFR and Pi3K inhibition}

This article is protected by copyright. All rights reserved. 
To confirm a role for EGFR on fibroblasts of patients with $\mathrm{SSc}$, we assessed its inhibition on fibroblast proliferation and survival. Proliferation and survival of fibroblasts from patients with SSc and/or $\mathrm{HC}$ were lower when cultured in the presence of cetuximab (Figure 3).

We also assessed Pi3K inhibition on proliferation and survival of fibroblasts from patients with SSc and healthy controls. Proliferation and survival of fibroblasts were lower when fibroblasts from patients with SSc were cultured in the presence of LY-294,002 (Figure 4A) which inhibits Pi3K $\alpha \beta$ and PI3K $\delta$ subunits. To confirm these results, we inhibit fibroblasts proliferation and survival with IC-87114, a selective PI3K $\delta$ subunit inhibitor and with pictilisib which is a selective Pi3K $\alpha \beta$ and PI3K $\delta$ subunits. Interestingly, proliferation and survival of fibroblasts were not modified by addition of IC-87114 (Figure 4B) whereas pictilisib decreases fibroblasts proliferation and survival after 48 hours of culture (Figure 4C) suggesting that PI3K $\alpha \beta$ subunits play a role in fibroblasts proliferation and survival.

\section{DISCUSSION}

Using 2D-DIGE, we compared the proteomes of fibroblasts from patients with $\mathrm{SSc}$ and $\mathrm{HC}$ and highlighted important differences between groups. We also emphasized differences between groups in the protein expression profiles of fibroblasts cultured in the presence of TGF- $\beta$.

Consistent with previously reported proteomic analysis of different starting substrates from patients with SSc (whole skin, secretome, matrix and fibroblast layer lysate), we identified proteins involved in cytoskeleton organization, cellular process and metabolic process ${ }^{[28-33]}$. Mainly, we found an upregulation of Trio and F-actin binding protein and LIM domain and actin-binding protein 1 which are known to play a role in actin modification and contractility. We found that IQGAP1, which is a key player of fibroblast migration, was downregulated in SSc skin fibroblasts. Interestingly, IQGAP1 has already been found to be deregulated in fibroblasts from patients with $\mathrm{SSc}^{[34]}$. Indeed it was

This article is protected by copyright. All rights reserved. 
reported to be upregulated in lung fibroblasts from patients with SSc when activated with connective tissue growth factor ${ }^{[34]}$. Herein activation with TGF- $ß$ did not upregulate IQGAP1. Taken together these findings suggest that lung involvement in SSc depends on proteomic modification including modulation of IQGAP1. More recently, Corallo et al reported that involved skin is reactive to type-1 collagen and vimentin when compared to uninvolved skin ${ }^{[33]}$. Our data support that the production of type- 1 collagen is linked to TGF- $\beta$ stimulation but not spontaneous nor specific of SSc fibroblasts. Regarding vimentin that we found downregulated in fibroblasts from patients with SSc, the discrepancy with the work by Corallo et al highlights possible changes in fibroblast proteomic phenotype during disease evolution ${ }^{[33]}$.

Our work reinforces the role of TGF- $\beta$ in SSc as it shows that fibroblasts from patients with SSc have a high responsiveness to this cytokine. TGF- $\beta$ plays a pivotal role in the pathogenesis of fibrosis ${ }^{[16]}$. TGF- $\beta$ stimulates fibroblast differentiation, proliferation and survival, and collagen and other extracellular matrix component synthesis ${ }^{[35]}$. Fibroblasts from patients with SSc are characterized by an increased expression and function of TGF- $\beta$ receptors, partly due to a decreased expression of caveolin ${ }^{[35,36]}$. Even if we did not find caveolin downregulation, our results emphasise this increased response of fibroblasts from patients with SSc to TGF- $\beta$. Indeed addition of TGF- $\beta$ to the culture of fibroblasts from patients with SSc strongly enhanced their proteome expression, which remained similar to the one of fibroblasts from $\mathrm{HC}$ when cultured in the presence of TGF- $\beta$. Interestingly, although biological processes remain similar in the presence or in the absence of TGF- $\beta$, the number of protein pathways was increased by the addition of TGF- $\beta$. Noteworthy, the enhanced phenotype was characterized by increased production of actin cytoskeleton proteins and integrins. This upregulation of integrin production is in agreement with the work of Gerber et al who advocated a role for integrin-modulating therapy in mouse models of scleroderma. In two different mouse models of stiff skin syndrome, an early-stage mouse model for skin fibrosis, the authors were able to prevent

This article is protected by copyright. All rights reserved. 
skin fibrosis by modulating $\beta 1$ or $\beta 3$ integrins and reversed it by TGF- $\beta$ antagonism ${ }^{[37,38]}$. Interestingly, fibroblasts from patients with $\mathrm{SSc}$ were nearly 1.5 times more modified by the addition of TGF- $\beta$. It emphasizes that fibroblasts from patients with SSc have at least a quantitatively higher response to TGF- $\beta$ than fibroblasts from $\mathrm{HC}$ suggesting that fibroblast activation pathways are facilitated in SSc. Taken together these results emphasize the role of the integrin pathway and support the inhibition of TGF- $\beta$ in SSc.

Interestingly we identified EGFR and Pi3K as two proteins of interest in our network analysis. EGFR is expressed at the surface of fibroblasts and involved in fibrotic process. In vivo mouse studies showed that renal fibrosis requires both expression and activation of EGFR. Tang et al studied mice lacking EGFR and showed that they had less renal fibrosis after renal ischemia injury ${ }^{[39]}$. This fibrosis was shown to be dependent on TGF- $\beta 1$ genes which required EGFR activation ${ }^{[40]}$. EGFR influences both fibroblast and myofibroblast functions. Giordani et al reported that fetal lung fibroblasts lacking EGFR had decreased apoptosis and inflammation ${ }^{[41]}$. Migley et al reported in turn that TGF-ß1stimulated fibroblasts to myofibroblasts differentiation requires EGFR localization in lipid rafts ${ }^{[42]}$. Lastly Yoo et al showed that activated myofibroblasts expressed increased amounts of EGFR ${ }^{[43]}$. In the setting of SSc, Tokiyama et al were among the first ones to report EGFR abnormalities in SSc fibroblasts including decreased affinity for EGF, higher levels of RNA for EGFR gene and decrease response to transretinoic acid ${ }^{[44]}$. More recently, Arts et al demonstrated that remodelling signalling events occur through the EGFR in vascular smooth muscle cells stimulated by immunoglobulin $G$ from SSc patients ${ }^{[45]}$. Of note, we have previously shown that immunoglobulin G from patients with SSc target Pi3K ${ }^{[46]}$. Among autoantibodies found in patients with SSc, Planque et al. detected increased amounts of autoantibodies targeting the recombinant extracellular domain of EGF ${ }^{[47]}$. Yamane et al reported EGF regulated expression of TGF- $\beta$ receptor type II in human skin fibroblasts by Pi3K/Akt signalling pathway and that abnormal activation of EGF-mediated signalling pathway

This article is protected by copyright. All rights reserved. 
including Pi3K might play a role in TGF- $\beta$ receptor type II in SSc fibroblasts ${ }^{[48]}$. Last but not least, Lofgren et al. reported very recently that 4 of 11 EGFR ligands as well as the PI3K/Akt pathway could be linked to the transcriptional signature of SSc in a multicohort analysis ${ }^{[49]}$. Taken together our present work and previously reported results emphasize the role of EGFR in fibroblasts in SSc.

Our study has some limitations. As often when performing two-dimensional gel electrophoresis and mass spectrometry, this analysis was performed on a small number of patients and unmatched controls. Still, these techniques are powerful tools for proteomic analyses and we believe we identified interesting proteins, biological process and pathways in the specific settings of diffuse SSc which remains a rare and severe disease. Although we were able to identify a mean of 2713 different protein spots, some proteins were lost at each step of the experimental procedure and during the protein identification process. In addition, more than one protein was identified in numerous protein spots and it is not possible to assess the impact of each protein on the observed difference. Lastly, our results need to be confirmed in vivo and in additional patients and cohorts.

To conclude, we here confirm that the proteomic profile of fibroblasts differs between patients with SSc and $\mathrm{HC}$ and demonstrate that fibroblasts change their protein expression profile and expand the number of protein pathways upon stimulation with TGF- $\beta$. We highlighted that EGFR and PI3K might be proteins of interest in the setting of SSc. In vivo studies will be needed to confirm the potential efficacy of EGFR / Pi3K inhibition in SSc.

\section{ACKNOWLEDGEMENTS}

The authors are grateful to Dr Marie-Laure Brandely and Dr Isabelle Lopez for their valuable contribution to this work.

$\mathrm{BC}$ received financial support from the Société Nationale Française de Médecine Interne.

This article is protected by copyright. All rights reserved. 
The authors have no conflict of interest to declare.

\section{REFERENCES}

[1] N. Dumoitier, S. Lofek, L. Mouthon, Presse Médicale Paris Fr. 1983 2014, 43, e267.

[2] Y. Y. Ho, D. Lagares, A. M. Tager, M. Kapoor, Nat. Rev. Rheumatol. 2014, 10, 390.

[3] V. D. Steen, T. A. Medsger, Ann. Rheum. Dis. 2007, 66, 940.

[4] A. Gabrielli, E. V. Avvedimento, T. Krieg, N. Engl. J. Med. 2009, 360, 1989.

[5] E. C. LeRoy, J. Clin. Invest. 1974, 54, 880.

[6] B. Santiago, M. Galindo, M. Rivero, J. L. Pablos, Arthritis Rheum. 2001, 44, 1667.

[7] A. J. van der Slot, A.-M. Zuurmond, A. F. J. Bardoel, C. Wijmenga, H. E. H. Pruijs, D. O. Sillence, J. Brinckmann, D. J. Abraham, C. M. Black, N. Verzijl, J. DeGroot, R. Hanemaaijer, J. M. TeKoppele, T. W. J. Huizinga, R. A. Bank, J. Biol. Chem. 2003, 278, 40967.

[8] A. E. Postlethwaite, M. A. Holness, H. Katai, R. Raghow, J. Clin. Invest. 1992, 90, 1479.

[9] K. Khan, S. Xu, S. Nihtyanova, E. Derrett-Smith, D. Abraham, C. P. Denton, V. H. Ong, Ann. Rheum. Dis. 2012, 71, 1235.

[10] N. Dumoitier, B. Chaigne, A. Régent, S. Lofek, M. Mhibik, P. Dorfmüller, B. Terrier, J. London, A. Bérezné, N. Tamas, N. Varin-Blank, L. Mouthon, Arthritis Rheumatol. Hoboken NJ 2016, DOI 10.1002/art.40016.

[11] A. Leask, D. J. Abraham, J. Cell Sci. 2006, 119, 4803.

[12] A. Ludwicka, T. Ohba, M. Trojanowska, A. Yamakage, C. Strange, E. A. Smith, E. C. Leroy, S. Sutherland, R. M. Silver, J. Rheumatol. 1995, 22, 1876.

[13] P. Sambo, S. S. Baroni, M. Luchetti, P. Paroncini, S. Dusi, G. Orlandini, A. Gabrielli, Arthritis Rheum. 2001, 44, 2653.

[14] C. Chizzolini, E. Raschi, R. Rezzonico, C. Testoni, R. Mallone, A. Gabrielli, A. Facchini, N. Del Papa, M. O. Borghi, J. M. Dayer, P. L. Meroni, Arthritis Rheum. 2002, 46, 1602.

[15] S. S. Baroni, M. Santillo, F. Bevilacqua, M. Luchetti, T. Spadoni, M. Mancini, P. Fraticelli, P. Sambo, A. Funaro, A. Kazlauskas, E. V. Avvedimento, A. Gabrielli, N. Engl. J. Med. 2006, 354, 2667.

[16] R. Lafyatis, Nat. Rev. Rheumatol. 2014, 10, 706.

[17] M. E. Johnson, J. M. Mahoney, J. Taroni, J. L. Sargent, E. Marmarelis, M.-R. Wu, J. Varga, M.

This article is protected by copyright. All rights reserved. 
E. Hinchcliff, M. L. Whitfield, PloS One 2015, 10, e0114017.

[18] S. Assassi, M. D. Mayes, Curr. Opin. Rheumatol. 2013, 25, 686.

[19] J. L. Sargent, A. Milano, S. Bhattacharyya, J. Varga, M. K. Connolly, H. Y. Chang, M. L. Whitfield, J. Invest. Dermatol. 2010, 130, 694.

[20] P. P. Sfikakis, B. K. McCune, M. Tsokos, K. Aroni, G. Vayiopoulos, G. C. Tsokos, Clin. Immunol. Immunopathol. 1993, 69, 199.

[21] L. M. Rice, C. M. Padilla, S. R. McLaughlin, A. Mathes, J. Ziemek, S. Goummih, S. Nakerakanti, M. York, G. Farina, M. L. Whitfield, R. F. Spiera, R. B. Christmann, J. K. Gordon, J. Weinberg, R. W. Simms, R. Lafyatis, J. Clin. Invest. 2015, 125, 2795.

[22] J. Varga, D. Abraham, J. Clin. Invest. 2007, 117, 557.

[23] F. van den Hoogen, D. Khanna, J. Fransen, S. R. Johnson, M. Baron, A. Tyndall, M. MatucciCerinic, R. P. Naden, T. A. Medsger, P. E. Carreira, G. Riemekasten, P. J. Clements, C. P. Denton, O. Distler, Y. Allanore, D. E. Furst, A. Gabrielli, M. D. Mayes, J. M. van Laar, J. R. Seibold, L. Czirjak, V. D. Steen, M. Inanc, O. Kowal-Bielecka, U. Müller-Ladner, G. Valentini, D. J. Veale, M. C. Vonk, U. A. Walker, L. Chung, D. H. Collier, M. E. Csuka, B. J. Fessler, S. Guiducci, A. Herrick, V. M. Hsu, S. Jimenez, B. Kahaleh, P. A. Merkel, S. Sierakowski, R. M. Silver, R. W. Simms, J. Varga, J. E. Pope, Arthritis Rheum. 2013, 65, 2737.

[24] A. Régent, K. H. Ly, S. Lofek, G. Clary, M. Tamby, N. Tamas, C. Federici, C. Broussard, P. Chafey, E. Liaudet-Coopman, M. Humbert, F. Perros, L. Mouthon, Proteomics 2016, 16, 2637.

[25] A. Régent, S. Lofek, H. Dib, G. Bussone, N. Tamas, C. Federici, C. Broussard, L. Guillevin, L. Mouthon, Clin. Immunol. Orlando Fla 2014, 153, 123.

[26] H. Dib, P. Chafey, G. Clary, C. Federici, M. Le Gall, J. Dwyer, J. Gavard, N. Tamas, G. Bussone, C. Broussard, L. Camoin, V. Witko-Sarsat, M. C. Tamby, L. Mouthon, Proteomics 2012, 12, 2547.

[27] H. Mi, A. Muruganujan, J. T. Casagrande, P. D. Thomas, Nat. Protoc. 2013, 8, 1551.

[28] N. Aden, X. Shiwen, D. Aden, C. Black, A. Nuttall, C. P. Denton, A. Leask, D. Abraham, R. Stratton, Rheumatol. Oxf. Engl. 2008, 47, 1754.

[29] G. S. Bogatkevich, A. Ludwicka-Bradley, C. B. Singleton, J. R. Bethard, R. M. Silver, Am. J. Physiol. Lung Cell. Mol. Physiol. 2008, 295, L603.

[30] F. Del Galdo, M. A. Shaw, S. A. Jimenez, Am. J. Pathol. 2010, 177, 1638.

[31] C. Landi, E. Bargagli, L. Bianchi, A. Gagliardi, A. Carleo, D. Bennett, M. G. Perari, A. Armini, A. Prasse, P. Rottoli, L. Bini, J. Proteomics 2013, 83, 60.

This article is protected by copyright. All rights reserved. 
[32] L. van Bon, M. Cossu, A. Loof, F. Gohar, H. Wittkowski, M. Vonk, J. Roth, W. van den Berg, W. van Heerde, J. C. A. Broen, T. R. D. J. Radstake, Ann. Rheum. Dis. 2014, 73, 1585.

[33] C. Corallo, A. Santucci, G. Bernardini, N. Figura, R. Leoncini, G. Riolo, A. Montella, C. Chirico, R. Nuti, N. Giordano, J. Rheumatol. 2017, 44, 40.

[34] G. S. Bogatkevich, A. Ludwicka-Bradley, C. B. Singleton, J. R. Bethard, R. M. Silver, Am. J. Physiol. Lung Cell. Mol. Physiol. 2008, 295, L603.

[35] A. Usategui, M. J. del Rey, J. L. Pablos, Expert Rev. Clin. Immunol. 2011, 7, 491.

[36] F. Del Galdo, F. Sotgia, C. J. de Almeida, J.-F. Jasmin, M. Musick, M. P. Lisanti, S. A. Jiménez, Arthritis Rheum. 2008, 58, 2854.

[37] E. E. Gerber, E. M. Gallo, S. C. Fontana, E. C. Davis, F. M. Wigley, D. L. Huso, H. C. Dietz, Nature 2013, 503, 126.

[38] K. Ray, Nat. Rev. Rheumatol. 2013, 9, 637.

[39] J. Tang, N. Liu, E. Tolbert, M. Ponnusamy, L. Ma, R. Gong, G. Bayliss, H. Yan, S. Zhuang, Am. J. Pathol. 2013, 183, 160.

[40] R. Samarakoon, A. D. Dobberfuhl, C. Cooley, J. M. Overstreet, S. Patel, R. Goldschmeding, K. K. Meldrum, P. J. Higgins, Cell. Signal. 2013, 25, 2198.

[41] V. M. Giordani, C. M. DeBenedictus, Y. Wang, J. Sanchez-Esteban, J. Recept. Signal Transduct. Res. 2014, 34, 58.

[42] A. C. Midgley, M. Rogers, M. B. Hallett, A. Clayton, T. Bowen, A. O. Phillips, R. Steadman, J. Biol. Chem. 2013, $288,14824$.

[43] J. Yoo, C. E. Rodriguez Perez, W. Nie, R. A. Edwards, J. Sinnett-Smith, E. Rozengurt, Am. J. Physiol. Gastrointest. Liver Physiol. 2012, 302, G805.

[44] K. Tokiyama, E. Yokota, Y. Niho, J. Rheumatol. 1990, 17, 1463.

[45] M. R. Arts, M. Baron, N. Chokr, M. J. Fritzler, Canadian Scleroderma Research Group (CSRG), M. J. Servant, PloS One 2014, 9, e100035.

[46] B. Terrier, M. C. Tamby, L. Camoin, P. Guilpain, A. Bérezné, N. Tamas, C. Broussard, F. Hotellier, M. Humbert, G. Simonneau, L. Guillevin, L. Mouthon, Ann. Rheum. Dis. 2010, 69, 428.

[47] S. Planque, Y.-X. Zhou, Y. Nishiyama, M. Sinha, M. O’Connor-Mccourt, F. C. Arnett, S. Paul, FASEB J. Off. Publ. Fed. Am. Soc. Exp. Biol. 2003, 17, 136.

[48] K. Yamane, H. Ihn, K. Tamaki, Arthritis Rheum. 2003, 48, 1652.

This article is protected by copyright. All rights reserved. 
[49] S. Lofgren, M. Hinchcliff, M. Carns, T. Wood, K. Aren, E. Arroyo, P. Cheung, A. Kuo, A. Valenzuela, A. Haemel, P. J. Wolters, J. Gordon, R. Spiera, S. Assassi, F. Boin, L. Chung, D. Fiorentino, P. J. Utz, M. L. Whitfield, P. Khatri, JCI Insight 2016, 1, e89073.

\section{TABLE}

Table 1. Numbers of protein spots differentially expressed between fibroblasts of patients with diffuse systemic sclerosis and fibroblasts of healthy controls, cultured in the presence or in the absence of transforming growth factor-ß

\begin{tabular}{lcccc}
\hline & $\begin{array}{c}\text { SSc vs } \\
\text { HC }\end{array}$ & $\begin{array}{c}\text { SScT vs } \\
\text { HCT }\end{array}$ & $\begin{array}{c}\text { SScT vs } \\
\text { SSc }\end{array}$ & $\begin{array}{c}\text { HCT vs } \\
\text { HC }\end{array}$ \\
\hline $\begin{array}{l}\text { Number of protein spots differentially } \\
\text { expressed (fold change } \geq \mathbf{1 . 3} \text { ) }\end{array}$ & $\mathbf{4 2}$ & $\mathbf{3 4}$ & $\mathbf{2 3 5}$ & $\mathbf{1 6 2}$ \\
& 17 & 18 & 111 & 100 \\
$\begin{array}{l}\text { Number of protein spots differentially } \\
\text { expressed (fold change } \geq \mathbf{1 . 5} \text { ) }\end{array}$ & $\mathbf{2 1}$ & 16 & 124 & 62 \\
& 14 & 12 & 110 & 87 \\
$\begin{array}{l}\text { Number of protein spots differentially } \\
\text { expressed (fold change } \geq \mathbf{2 . 0}\end{array}$ & 7 & 8 & 122 & 49 \\
& $\mathbf{2}$ & $\mathbf{4}$ & $\mathbf{6 8}$ & $\mathbf{6 6}$ \\
& 2 & 4 & 43 & 49 \\
\hline
\end{tabular}

HC: fibroblasts from healthy controls, HCT: fibroblasts from healthy controls cultured with TGF- $\beta$, SSc: fibroblasts from patients with systemic sclerosis, SScT: fibroblasts from patients with systemic sclerosis cultured with TGF- $\beta$, TGF- $\beta$ : transforming growth factor- $\beta$

This article is protected by copyright. All rights reserved. 
Table 2. Gene ontology biological processes associated to proteins differentially expressed between fibroblasts of patients with diffuse systemic sclerosis and fibroblasts of healthy controls, cultured in the presence or in the absence of transforming growth factor- $-\beta$

$\operatorname{David}^{\circledR}$ functional classification software was used to assess the gene ontology biological processes associated to proteins found in statistically significant altered abundance in fibroblasts from patients with diffuse systemic sclerosis compared to fibroblasts from healthy controls cultured in the presence or in the absence of transforming growth factor- $\beta$

\begin{tabular}{|c|c|c|c|}
\hline SSc vs HC & & SScT vs HCT & \\
\hline Biological process & $\%$ & Biological process & $\%$ \\
\hline Cell-cell adhesion & 12,2 & Cell-cell adhesion & 14,3 \\
\hline Carbohydrate metabolic process & 10,2 & $\begin{array}{l}\text { Movement of cell or subcellular } \\
\text { component }\end{array}$ & 11,4 \\
\hline IRE1-mediated unfolded protein response & 8,2 & Muscle contraction & 11,4 \\
\hline Movement of cell or subcellular component & 8,2 & Epithelial cell differentiation & 11,4 \\
\hline Integrin-mediated signaling pathway & 8,2 & Muscle filament sliding & 8,6 \\
\hline Leukocyte migration & 8,2 & Response to ethanol proliferation & 8,6 \\
\hline Positive regulation of gene expression & 8,2 & Regulation of cell shape & 8,6 \\
\hline Protein transport & 8,2 & $\begin{array}{l}\text { Positive regulation of superoxide anion } \\
\text { generation }\end{array}$ & 5,7 \\
\hline $\begin{array}{l}\text { Antigen processing and presentation of exogenous } \\
\text { peptide antigen via MHC class I, TAP-dependent }\end{array}$ & 6,1 & Ruffle organization & 5,7 \\
\hline Negative regulation of catalytic activity & 6,1 & Regulation of muscle contraction & 5,7 \\
\hline Cell-matrix adhesion & 6,1 & $\begin{array}{l}\text { Negative regulation of vascular smooth } \\
\text { muscle cell }\end{array}$ & 5,7 \\
\hline Protein folding & 6,1 & Cellular amino acid biosynthetic process & 5,7 \\
\hline
\end{tabular}

This article is protected by copyright. All rights reserved. 
Positive regulation of vesicle fusion

UDP-N-acetylglucosamine biosynthetic process

Positive regulation of NIK/NF-kappaB signaling

Cell adhesion mediated by integrin

Stress fiber assembly

Cell-substrate adhesion

Heterotypic cell-cell adhesion

Leukocyte cell-cell adhesion

Endodermal cell differentiation

Actin filament bundle assembly

Positive regulation of establishment of protein localization to plasma membrane
4,1 Response to organic substance $\quad 5,7$

4,1 Regulation of heart contraction $\quad 5,7$

4,1 Chaperone-mediated protein folding $\quad 5,7$

4,1 Negative regulation of extrinsic apoptotic signaling pathway

4,1 Response to reactive oxygen species $\quad 5,7$

4,1 Protein peptidyl-prolyl isomerization $\quad 5,7$

4,1

4,1

4,1

4,1

\begin{tabular}{lcll}
\hline \multicolumn{1}{c}{ SScT vs SSc } & & & HCT vs HC \\
\hline Biological process & $\%$ & Biological process & $\%$ \\
Cell-cell adhesion & 10,9 & Cell-cell adhesion & 13,9 \\
oxidation-reduction process & 10,4 & Negative regulation of apoptotic process & 7,3 \\
Negative regulation of apoptotic process & 9,4 & Oxidation-reduction process & 7,3 \\
Movement of cell or subcellular component & 4,5 & Protein transport & 5,8 \\
Intracellular protein transport & 4,5 & Platelet aggregation & 5,1 \\
& & Movement of cell or subcellular & \\
Response to drug & 4,5 & component & 5,1 \\
Cytoskeleton organization & 4 & Leukocyte migration & 5,1 \\
Protein folding & 4 & Protein folding & 5,1 \\
Epithelial cell differentiation & 3,5 & Extracellular matrix organization \\
Cell redox homeostasis & 3,5 & Intracellular protein transport & 5,1
\end{tabular}

This article is protected by copyright. All rights reserved. 
Regulation of cell shape

Response to reactive oxygen species

Platelet aggregation

Response to endoplasmic reticulum stress

Response to ethanol

Leukocyte migration

Extracellular matrix organization
3,5 Response to endoplasmic reticulum stress

3 Muscle contraction

3 Response to drug

3

Cell redox homeostasis

3 Osteoblast differentiation

3

Regulation of cell shape

3

Cytoskeleton organization

Positive regulation of cell migration

HC: fibroblasts from healthy controls, HCT: fibroblasts from healthy controls cultured with TGF- $\beta$, SSc: fibroblasts from patients with systemic sclerosis, SScT: fibroblasts from patients with systemic sclerosis cultured with TGF- $\beta$, TGF- $\beta$ : transforming growth factor- $\beta$

This article is protected by copyright. All rights reserved. 
Table 3. Gene ontology pathways associated to proteins differentially expressed between fibroblasts of patients with diffuse systemic sclerosis and fibroblasts of healthy controls, cultured in the presence or in the absence of transforming growth factor-ß

$\operatorname{David}^{\circledR}$ functional classification software was used to assess the gene ontology pathways associated to proteins found in statistically significant altered abundance in fibroblasts from patients with diffuse systemic sclerosis compared to fibroblasts from healthy controls cultured in the presence or in the absence of transforming growth factor $-\beta$

\begin{tabular}{|c|c|c|c|}
\hline \multirow[t]{2}{*}{ SSc vs HC } & \multicolumn{3}{|c|}{ SScT vs HCT } \\
\hline & $\%$ & Pathway & $\%$ \\
\hline Focal adhesion & 14,3 & Regulation of actin cytoskeleton & 11,4 \\
\hline Regulation of actin cytoskeleton & 14,3 & MicroRNAs in cancer & 11,4 \\
\hline Proteoglycans in cancer & 12,2 & Hypertrophic cardiomyopathy (HCM) & 8,6 \\
\hline PI3K-Akt signaling pathway & 10,2 & Dilated cardiomyopathy & 8,6 \\
\hline \multicolumn{4}{|l|}{ Arrhythmogenic right ventricular } \\
\hline cardiomyopathy (ARVC) & 8,2 & Alanine, aspartate and glutamate metabolism & 5,7 \\
\hline Hypertrophic cardiomyopathy (HCM) & 6,1 & & \\
\hline Dilated cardiomyopathy & 6,1 & & \\
\hline ECM-receptor interaction & 6,1 & & \\
\hline \multirow[t]{2}{*}{ SScT vs SSc } & \multicolumn{3}{|c|}{ HCT vs HC } \\
\hline & $\%$ & Pathway & $\%$ \\
\hline Metabolic pathways & 14,4 & Focal adhesion & 10,9 \\
\hline Regulation of actin cytoskeleton & 6,9 & Regulation of actin cytoskeleton & 10,2 \\
\hline Focal adhesion & 5,9 & Proteoglycans in cancer & 7,3 \\
\hline
\end{tabular}

This article is protected by copyright. All rights reserved. 
Tight junction

Protein processing in endoplasmic reticulum

Biosynthesis of antibiotics

Carbon metabolism

Phagosome

Shigellosis

Arrhythmogenic right ventricular

cardiomyopathy (ARVC)

Hypertrophic cardiomyopathy (HCM)

Salmonella infection

Fc gamma R-mediated phagocytosis

Dilated cardiomyopathy

ECM-receptor interaction

Pathogenic Escherichia coli infection

Biosynthesis of amino acids

Bacterial invasion of epithelial cells

Amoebiasis

Alanine, aspartate and glutamate metabolism

Arginine and proline metabolism

D-Glutamine and D-glutamate metabolism
$4 \quad$ PI3K-Akt signaling pathway

4 Protein processing in endoplasmic reticulum

4 Tight junction

3,5 Phagosome

Arrhythmogenic right ventricular

3,5 cardiomyopathy (ARVC)

3 Hypertrophic cardiomyopathy (HCM)

3 Dilated cardiomyopathy

3 ECM-receptor interaction

3 Shigellosis

3 Leukocyte transendothelial migration

3 Platelet activation

3 Bacterial invasion of epithelial cells

2,5 Amoebiasis

2,5 Pathogenic Escherichia coli infection

2,5 Adherens junction

2,5 Salmonella infection

2 Protein digestion and absorption

1

HC: fibroblasts from healthy controls, HCT: fibroblasts from healthy controls cultured with TGF- $\beta$, SSc: fibroblasts from patients with systemic sclerosis, SScT: fibroblasts from patients with systemic sclerosis cultured with TGF- $\beta$, TGF- $\beta$ : transforming growth factor- $\beta$

This article is protected by copyright. All rights reserved. 


\section{FIGURE LEGENDS}

Figure 1. Comparison of proteomes of fibroblasts from patients with diffuse systemic sclerosis (SSc) and healthy controls, cultured in the presence or in the absence of transforming growth

\section{factor-8}

Panel A: principal component analysis of the protein spots differentially expressed between fibroblasts of diffuse SSc patients $(n=4)$ and $\mathrm{HC}(\mathrm{n}=3)$ cultured in the presence or in the absence of TGF- $\beta$. Panel B: hierarchical clustering of protein spots displayed as a heat map. The color scale goes from green (decreased protein expression), to black (no change in protein expression), and to red (increased protein expression). White color represents a spot, which is not detected or matched.

HC: healthy controls; SSc: systemic sclerosis; TGF- $\beta$ : transforming growth factor- $\beta$.

A

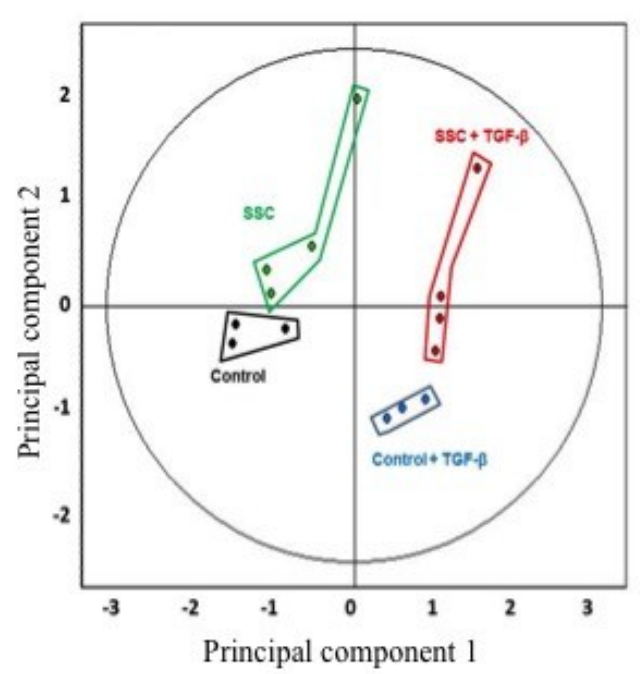

B

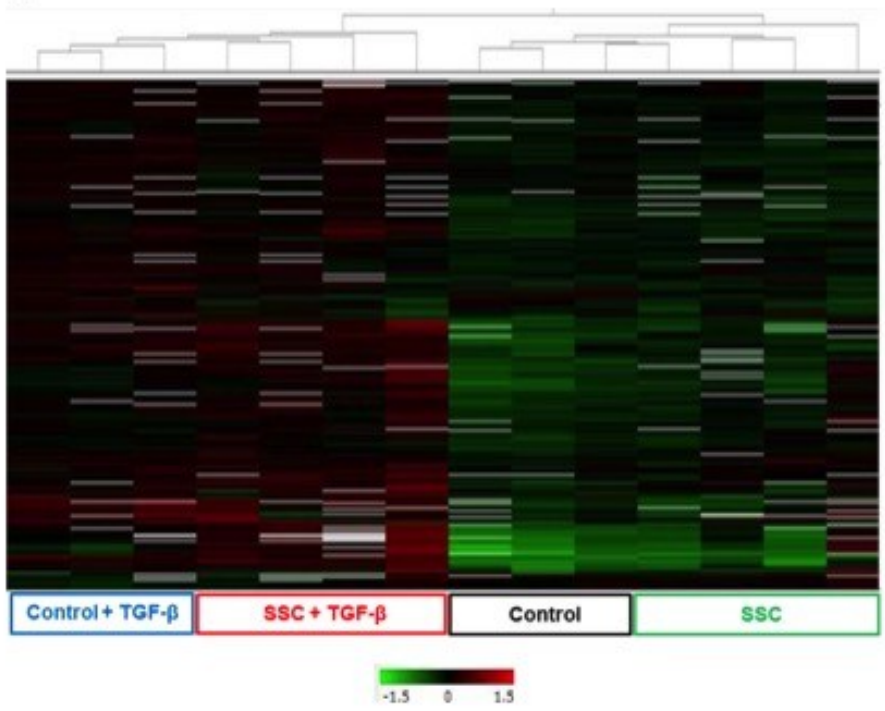

This article is protected by copyright. All rights reserved. 
Figure 2. Simplified network generated by Ingenuity pathway analysis with Human proteins identified as specific target antigens interacting with deregulated proteins of fibroblasts from patients with diffuse systemic sclerosis.

Network was generated by ingenuity pathway analysis (IPA) with identified proteins showing major differences in expression between fibroblasts from SSc patients and HC. Solid lines indicate direct interaction or regulation. Red nodes, up-regulated protein; green nodes, down-regulated protein; white nodes, protein added by IPA algorithm not present in our list of protein differentially expressed. The different shades of red and green reflect the relative fold change.

AHNAK: AHNAK nucleoprotein; ACTN4: actinin 4; ADAM 12: A disintegrin and metallopeptidase domain 12; Ck2: casein kinase 2; CTNNB1: catenin B1; EGFR: epidermal growth factor receptor; ENO2: enolase 2; ERK: extracellular receptor kinase; ESR1: estrogen receptor 1; IQGAP1: IQ motif containing GTPase activating protein 1; HEXIM1: hexamethylenee bis-acetamide inducible 1; HGS: hepatocyte growth factor - regulated tyrosine kinase substrate; HSP90B1: heat shock protein 90kDa bet family member 1; ITGAV: integrin subunit $\alpha \mathrm{V}$; ITGB1: integrin subunit $\beta 1$; LMNA: laminin A/C; MAP4: microtubule associated protein 4; MSN: moesin; MVP: major vault protein; NFкB: nuclear factor $\kappa B$; p85 pik3r: p85 subunit of phosphatidylinositol 3 - kinase receptor; PEA 15: phosphoprotein enriched in astrocytes 15; PGM3: phosphoglucomutase 3; Pka: A-kinase; RPS3: ribosomal protein S3; SRC; TLN1: Talin1; TP53: tumor protein 53; TGF B1: transforming growth factor B1; VIM: vimentin; XRCC5: X ray repair complementing defective repair in Chinese Hamster cells 5 .

This article is protected by copyright. All rights reserved. 


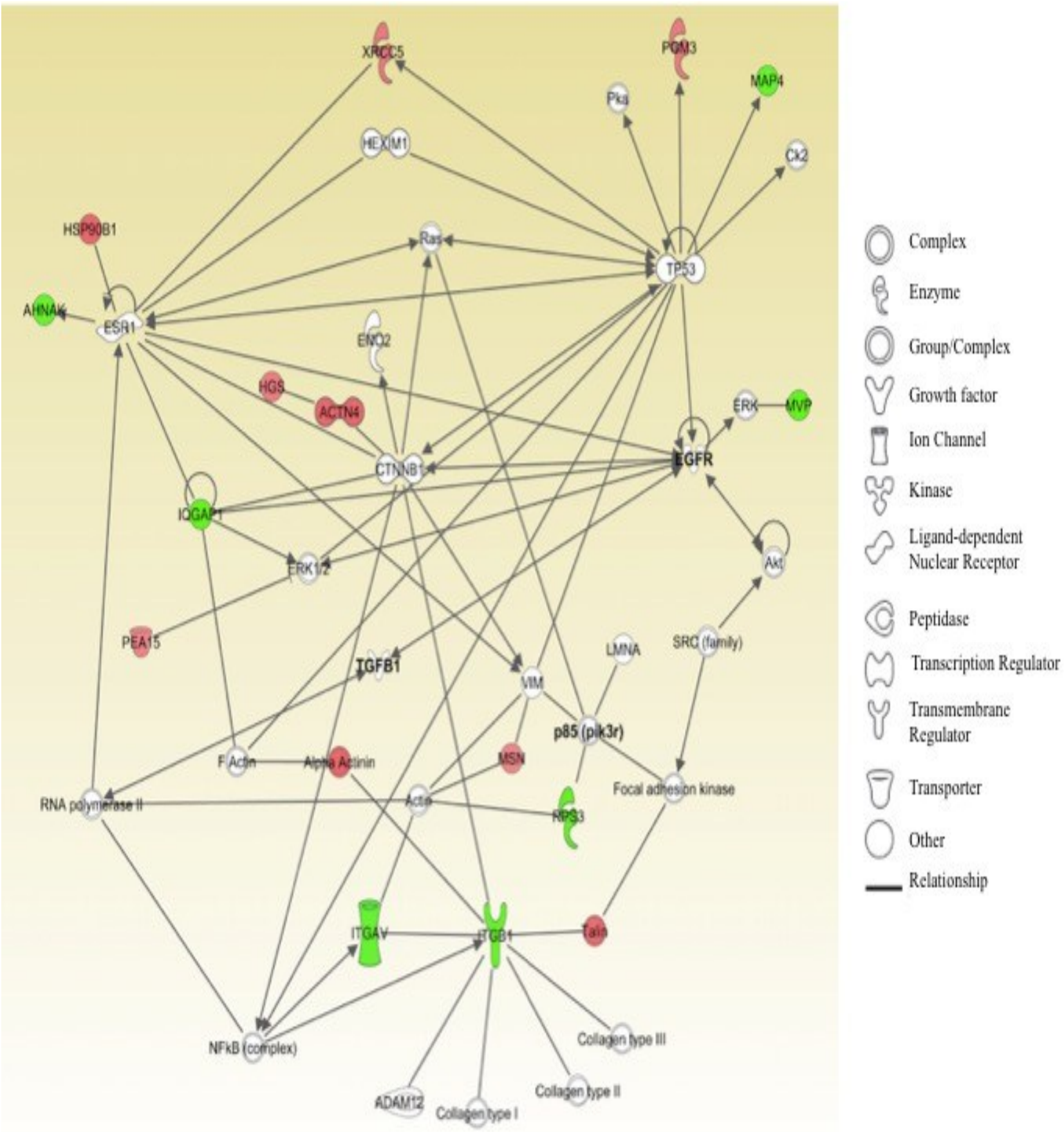

This article is protected by copyright. All rights reserved. 
Figure 3. Inhibition of epidermal growth factor receptor (EGFR) from patients with systemic sclerosis (SSc) and healthy controls (HC)

Fibroblasts (2500/well) isolated from $5 \mathrm{SSc}$ patients and $5 \mathrm{HC}$ were cultured alone, with a monoclonal immunoglobulin $\mathrm{G}$ from a patient with multiple myeloma, or with cetuximab for 3 days. Proliferation and adhesion were measured using the $\mathrm{xCELLigence}{ }^{\circledR}$ real time cell analysis instrument. This assay system expresses impedance in arbitrary cell index units. Comparisons were performed using a Friedman test. Statistical significance was defined as: * p-value $<0.05$.

EGFR: epidermal growth factor- receptor; HC: healthy control; Ig: immunoglobulin; SSc: Systemic sclerosis.

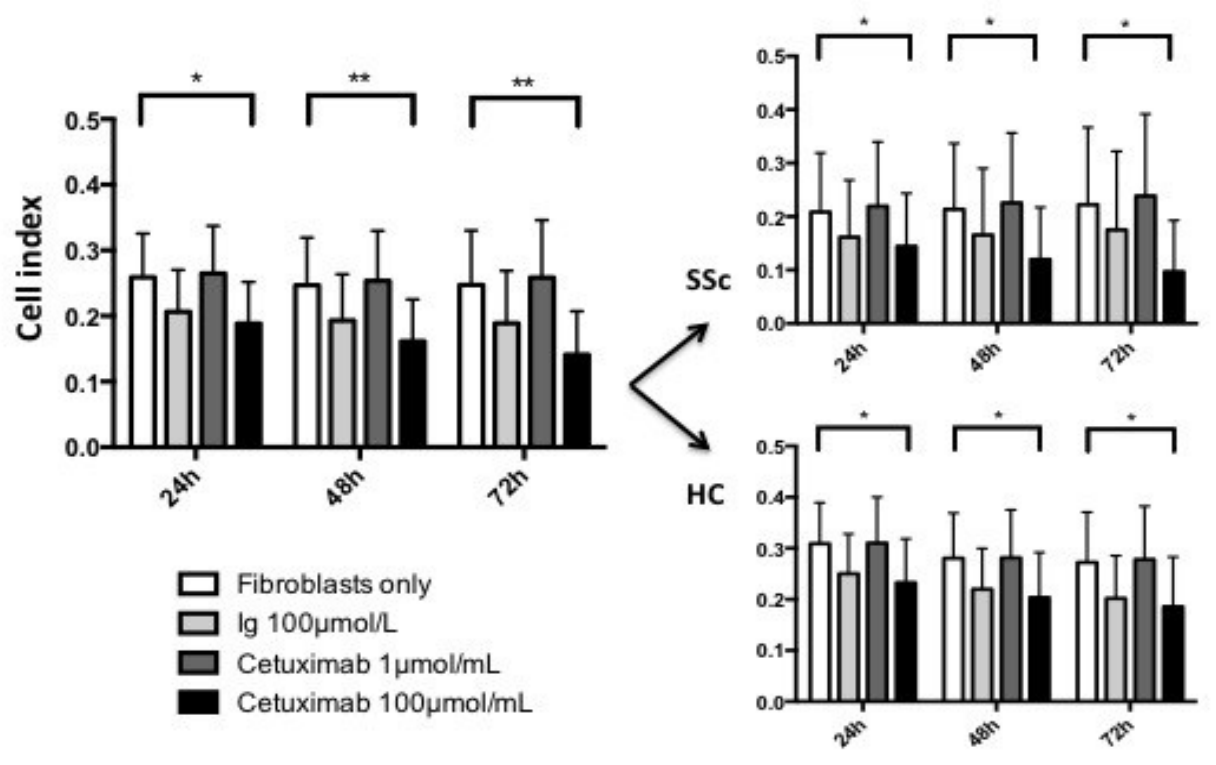

This article is protected by copyright. All rights reserved. 
Figure 4. Inhibition of phosphatidylinositol 3 kinase (Pi3K) in fibroblasts from patients with systemic sclerosis (SSc) and healthy controls (HC)

Panel A: fibroblasts (2500/well) isolated from $5 \mathrm{SSc}$ patients and $5 \mathrm{HC}$ were cultured alone, or with Ly294002 $(50 \mu \mathrm{M})$ for 3 days. Panel B: fibroblasts (2500/well) isolated from 5 SSc patients and 5 HC were cultured alone, or with IC-87114 $(0.5 \mu \mathrm{M})$ for 3 days. Panel C: fibroblasts (2500/well) isolated from $5 \mathrm{SSc}$ patients and $5 \mathrm{HC}$ were cultured alone, or with pictilisib (33nM) for 3 days.

Proliferation and adhesion were measured using the xCELLigence ${ }^{\circledR}$ real time cell analysis instrument. Vehicle of the small molecules was not added to controls. This assay system expresses impedance in arbitrary cell index units. Comparisons were performed using a Friedman test. Statistical significance was defined as: $*$ p-value $<0.05$.

Pi3K: phosphatidylinositol 3 - kinase; HC: healthy control; SSc: Systemic sclerosis.

A
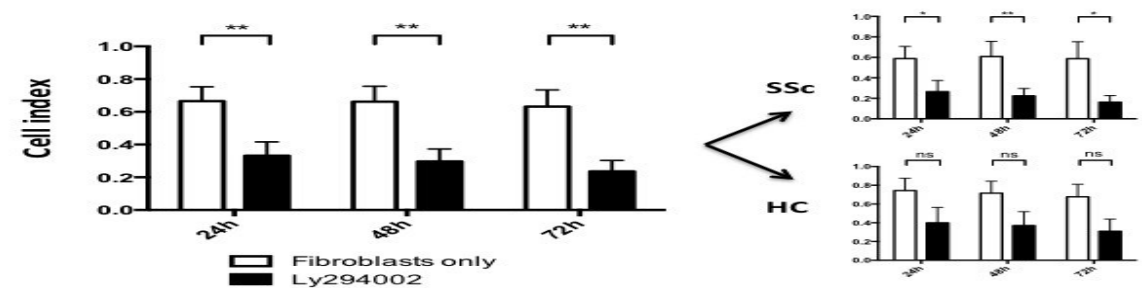

$\mathbf{B}$
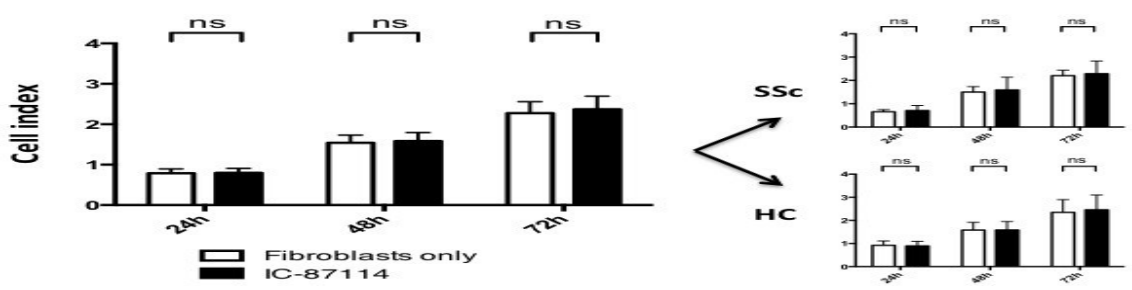

$c$
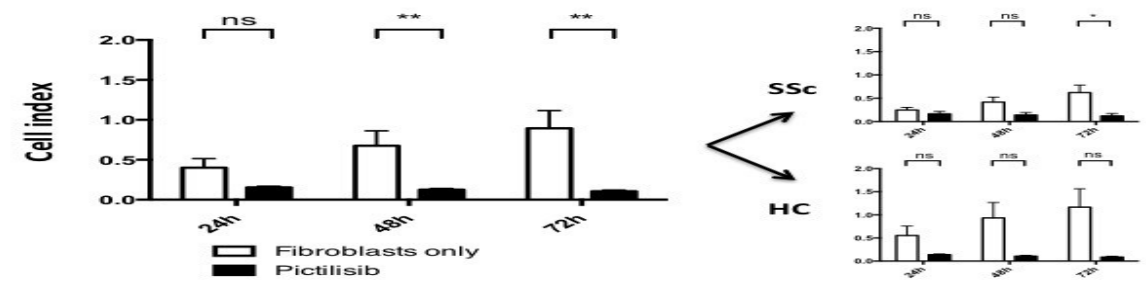

This article is protected by copyright. All rights reserved. 